secretary at the plant has been relieved of his post and other officials disciplined.

The Irbit factory is important in the Soviet Union's plans to build a sophisticated pharmaceutical and specialist chemical industry, and should be at the leading edge of the government's new drive for modernization. The intervention of the Central Committee, and the attention it has been given, may be intended as a warning to plant managers elsewhere that they had better put their affairs in order before the drive for modernization gathers momentum and that a random selection of scapegoats will not suffice.

Vera Rich

AIDS research

\section{New foundation begins work}

Washington

SUPPORT for research into acquired immune deficiency syndrome (AIDS) has received a shot in the arm from the American Foundation for AIDS Research (AmFAR). The new foundation handed out 20 grants totalling $\$ 1.1$ million, mostly for basic research on the biology of the virus assocaited with AIDS, with a smaller number for drug development and epidemiology. AmFAR's scientific advisory committee was looking primarily for projects demonstrating "fresh ideas", according to a spokesman for AmFAR.

The 20 projects receiving grants were chosen from 146 applications. The maximum $\$ 60,000$ grant is not intended to sustain a major research effort, but will instead provide start-up money for new projects.

AmFAR came into existence last September when the AIDS Medical Foundation, based in New York, merged with the National AIDS Research Foundation of Los Angeles. Actress Elizabeth Taylor serves as AmFAR's national chairman, and has been an active force in fundraising. In future, AmFAR hopes to move its financial base away from special fundraising events to long-term commitments from corporations and philanthropic foundations.

Although the $\$ 1.1$ million offered by AmFAR is only a small fraction of the \$233 million AIDS budget of the US Public Health Service, there is always enthusiasm for a new source of funds. "Any branch I can shake for support is marvellous," says Murray Gardner of the University of California at Davis, who received a $\$ 60,000$ grant from AmFAR to study the structure of the envelope protein of the AIDS virus.

AmFAR can also move more quickly than the federal government. It solicited proposals in January, and made decisions on them just 4 months later. Joseph Palca

Rice breeding

\title{
Manipulation of cereal succeeds
}

Tokyo

THE basic techniques for the genetic engineering of rice have been developed in research institutes in Japan. Several laboratories are racing to draw the techniques together so as to be the first to produce a genetically engineered rice plant. The development is important not only because genetic manipulation has so far been mostly confined to dicotyledonous plants but also because rice is the staple food of half the world's population.

The transfer of genetic material into cereal plants has hitherto been held up because they cannot be infected with the Agrobacterium species which have provided a simple route to the transfer of genes in dicotyledonous plants. But two new developments have given rise to optimism that genetic manipulation of rice will be possible in the near future.

The regeneration of whole rice plants from protoplasts (single rice cells stripped of their cell wall) is one way. Success has just been reported in print by Professor Yasuyuki Yamada's group at the Kyoto University Research Center for Cell and Tissue Culture (see Plant Cell Reports 5, $85 ; 1986)$. Two industrial laboratories, a joint laboratory run by Mitsubishi Chemical and Mitsubishi Corporation and Mitsui Toatsu's research laboratory have also described regeneration techniques at research meetings. Each group has its own method and it is too early to know which will prove most practical.

Yamada can regenerate tissue from protoplasts by the simple trick of adding calf serum, commonly used in the culture of animal cells, to his medium; after all, he says, a "plant protoplast is almost the same as an animal cell".

From one culture cell line, Yamada has been able to produce calli (undifferentiated tissue) from 10 per cent of protoplasts, many of which formed roots and shoots and developed into whole plants when transferred to regeneration medium. Although other strains produced calli, only one regenerated whole plants and there is evidence that the adult plants, now out in pots and the fields, are not entirely normal. Further work may thus be needed to make the regeneration method of general use.

The Mitsubishi group, led by Dr K. Shimamoto, appears to have had much broader success. It has successfully regenerated whole plants from protoplasts of five different genotypes, two of them major commercial cultivars. More than 300 plants have now been regenerated, and of these 120 are now growing in paddy fields. They can later be studied in detail for differences from the parent stock.

The innovations behind the Mitsubishi group's success is that, instead of making protoplasts from rice cell lines maintained for a long time in culture, they have induced calli from rice seeds. The protoplasts so produced are "young" and have strong morphogenic potential. In the past, this approach has not been favoured because cells in fresh culture from seed do not divide - overcoming this obstacle is the secret of Shimamoto's method.

The second group of advances, for the transfer of foreign genes into protoplasts, has also very recently been reported, and depends on the observation that protoplasts prepared from cultured callus cells and treated with polyethylene glycol will take up foreign DNA. Dr Uchimiya's group at the University of Tsukuba has successfully introduced a chimaeric gene containing an antibiotic resistance gene in experiments of this kind. He was not, however, able to regenerate plants from the transformed cells.

With both regeneration and transformation proved possible, the race is now on to "put both techniques in one hand", as Uchimiya says, and to produce the first genetically engineered rice plants. Judging from reports from the five or so laboratories carrying out similar work, the winner should be declared fairly soon.

The question remains of what useful application can come from the research. In theory, the potential is vast, for rice is the major source of carbohydrate for almost half of the world's population. But rice has been intensively improved by breeders for almost a century, while large increases in production can be expected in the poorer countries of Asia simply through extending irrigation. This makes Japanese companies wary about investing heavily in rice research, for even now rice can be grown in Japan only by maintaining an artificial price several times that of the world market.

Early on, genetic engineering may be used to make things easier for the conventional breeder. Male sterile lines, valuable in breeding new strains of rice, are hard to produce by ordinary methods but should be easily made by protoplast fusion. One protoplast carrying the cytoplasmic male sterility factor but with its nucleus inactivated can be fused with the desired strain of rice.

In the longer term there are the possibilities of transferring genes from other cereal crops that seem to perform more efficiently, introducing viral resistance genes and altering genes to improve the quality of the seed protein. Again, there are ten wild species of rice which present an almost untapped reserve of genetic variability. Protoplast fusion will make it accessible.

Alun Anderson 